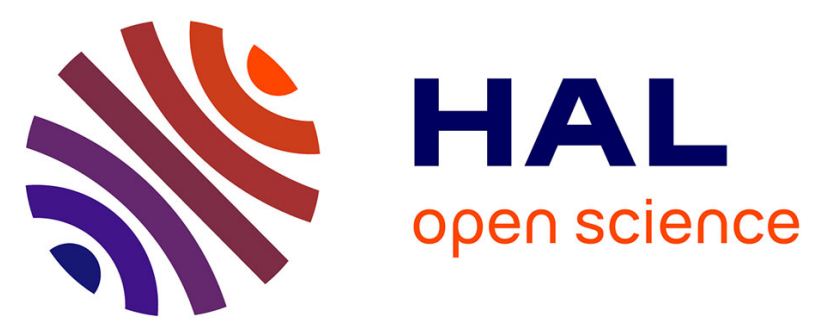

\title{
Assessment of the clinical relevance of pharmacists' interventions performed during medication review in a rheumatology ward
}

Anne-Laure Yailian, Elsa Revel, Cléa Tardy, Aurélie Fontana, Charline Estublier, Evelyne Decullier, Claude Dussart, Roland Chapurlat, Christine Pivot, Audrey Janoly-Dumenil

\section{To cite this version:}

Anne-Laure Yailian, Elsa Revel, Cléa Tardy, Aurélie Fontana, Charline Estublier, et al.. Assessment of the clinical relevance of pharmacists' interventions performed during medication review in a rheumatology ward. European Journal of Internal Medicine, 2019, 59, pp.91 - 96. 10.1016/j.ejim.2018.08.017 . hal-03485705

\section{HAL Id: hal-03485705 https://hal.science/hal-03485705}

Submitted on 20 Dec 2021

HAL is a multi-disciplinary open access archive for the deposit and dissemination of scientific research documents, whether they are published or not. The documents may come from teaching and research institutions in France or abroad, or from public or private research centers.
L'archive ouverte pluridisciplinaire HAL, est destinée au dépôt et à la diffusion de documents scientifiques de niveau recherche, publiés ou non, émanant des établissements d'enseignement et de recherche français ou étrangers, des laboratoires publics ou privés.

\section{(ㅇ)(1) $\$$}

Distributed under a Creative Commons Attribution - NonCommerciall 4.0 International 


\title{
Assessment of the clinical relevance of pharmacists' interventions performed during medication review in a rheumatology ward
}

\author{
AL Yailian ${ }^{1,2}$, E Revel $^{1}$, C Tardy ${ }^{1}$, A Fontana $^{3,4}$, C Estublier $^{3,4}$, \\ E Decullier ${ }^{5}, \mathrm{C}$ Dussart $^{2}, \mathrm{R}_{\text {Chapurlat }}{ }^{3,4}, \mathrm{C} \mathrm{Pivot}^{1}, \mathrm{~A}$ Janoly-Dumenil ${ }^{1,2,6}$
}

${ }^{1}$ Department of Pharmacy, Edouard Herriot Hospital, Hospices Civils de Lyon, 5 place d'Arsonval, 69003 Lyon, France.

${ }^{2}$ Claude Bernard University Lyon 1, EA 4129 P2S Parcours Santé Systémique, 7-11 rue Guilllaume Paradin, 69008 Lyon, France.

${ }^{3}$ Department of Rheumatology, Edouard Herriot Hospital, Hospices Civils de Lyon, 5 place d'Arsonval, 69003 Lyon, France.

${ }^{4}$ INSERM UMR 1033, Claude Bernard University Lyon 1, Laennec Faculty of Medicine, 7-11 rue Guillaume Paradin, 69008 Lyon, France.

${ }^{5}$ Department of Medical Information, Evaluation and Research, Clinical Research Unit, Hospices Civils de Lyon, 162 avenue Lacassagne, 69003 Lyon, France.

${ }^{6}$ Claude Bernard University Lyon 1, Faculty of Pharmacy, 8 avenue Rockefeller 69008 Lyon, France.

Number of words in the manuscript: 2527 words

Number of words in the abstract: 240 words

Number of references: 35 references

\section{Corresponding author:}

Anne-Laure Yailian

Tel.: +33(0)4 72117874

Fax: $+33(0) 472117876$

E-mail: annelaureyailian@gmail.com 


\begin{abstract}
Background: Pharmacists contribute to reduce the number of medication errors during medication review. Nevertheless, few French studies report the potential clinical impact of pharmacists' interventions performed after detecting drug-related problems. The objective was to evaluate the clinical relevance of pharmacists' interventions in a rheumatology ward from medical and pharmaceutical perspectives.
\end{abstract}

Method: The analysis was conducted on pharmacists' interventions performed between January 1 and December 31, 2015 in a French teaching hospital. Similar pharmacists' interventions were grouped in one item and they were analysed according to 11 drug categories. The clinical significance of pharmacists' interventions was considered independently by a pharmacist and a rheumatologist using a validated French scale that categorises drug-related problems from minor to catastrophic. The agreement between the two professionals was analysed using the weighted kappa coefficient.

Results: Of 1,313 prescriptions reviewed, 461 pharmacists' interventions (171 items) were formulated for drug-related problems with an acceptance rate of $67.2 \%$. Of the 418 interventions selected for clinical significance analysis, 235 interventions (56.2\%) for the physician and 400 interventions $(95.7 \%)$ for the pharmacist had at least significant. The two professionals evaluated equally the clinical relevance of 90 items $(50.6 \%)$. The categories with the most similarities were the analgesics/anti-inflammatory drugs (78.1\%), the antidiabetics $(75.0 \%)$ and the anticoagulants $(71.4 \%)$. The agreement was estimated by a weighted kappa coefficient of 0.29 .

Conclusion: This work highlights the positive clinical relevance of pharmacists' interventions in rheumatology and the importance of medico-pharmaceutical collaboration to prevent medication errors. 


\section{Keywords}

Pharmacists' interventions; medication review; drug-related problem; clinical impact; rheumatology. 


\section{Introduction}

In the hospital environment, patient medication management is a complex process. At each stage, there is a high iatrogenic risk [1]. A National survey on serious adverse events in hospitals in France demonstrated that medications are the second cause of serious adverse drug events (ADE) [2]. Among these ADE caused by medications, 15,000 to 60,000 could be avoided each year. The analysis of these adverse events shows that medication errors occur mostly at drug prescription stage [3-5], in $35 \%$ of cases. Through their activity of medication review, clinical pharmacists participate in controlling medication iatrogenesis. Considering to the Pharmaceutical Care Network Europe (PCNE), medication review is a 'structured evaluation of a patient's medicines with the aim of optimising medicines use and improving health outcomes', leading to the detection of 'drug-related problems and recommending interventions' [6]. Several international studies have demonstrated that medication review, along with the inclusion of a clinical pharmacist in the medical department, contributed to decrease medication errors (ME) [7-9], as well as in the length of hospital stay [10, 11], and mortality [12]. Clinical pharmacists can have a direct action through recommendations formulated during medication review to physicians. These pharmacists' interventions (PIs) are defined as 'any action initiated by a pharmacist directly resulting in a change in the patient's management or therapy' [13]. PIs include identification, prevention and resolution of drug-related problems (DRP) concerning prescriptions. Each PI may have an effect on patient management if it is accepted by the physician. Measurement of the potential clinical impact of PI is a notion that is still rarely examined in France $[14,15]$. Moreover, this measurement could be difficult since there is no consensus on which scale to use. Scales have been widely used: Hatoum et al. [16], Bayliff et al. [17], Overhage et al. [18], but they have not been adopted in current French practice. A recent French scale was validated in the study of Doerper et al. [19] to evaluate the severity of the potential harm of ME reported by 
medication reconciliation. This scale makes it possible to evaluate the clinical significance of detecting DRP at different stages and notably, at the prescription stage. Others scoring methods for assessing the potential impact of medication review have been described in the literature [20-22]. To our knowledge, there is no French study concerning the potential clinical impact of PIs in rheumatology.

\section{Aim of the study}

The objective of the study was to evaluate the clinical relevance of PIs performed during medication review in a rheumatology ward from medical and pharmaceutical perspectives.

\section{Ethics approval}

This was a retrospective study using only routine care data and anonymized data. Therefore, no ethical approval was deemed required.

\section{Method}

The study was conducted in a rheumatology department with 31 beds of a French University Hospital. Computerized prescriptions $\left(\right.$ CristalNet $^{\circledR}$ software) are reviewed by senior pharmacists or resident pharmacists on a daily basis for input prescriptions following the French Society of Clinical Pharmacy (SFPC) methodology [23]. Resident pharmacists are trained, validated and supervised by a senior pharmacist experienced. Medication review is based on medication history, medical information (clinical, biological and pathophysiological data) and therapeutic objectives (type 2B according to the PCNE [6] or level 2 according to the SFPC [24]). PIs are performed by pharmacists or resident pharmacists and classified according to the SFPC recommendations [25]: identification of the DRP (10 items), pharmacist's intervention (7 items) and acceptance by the prescriber (table 1). Physician 
acceptance of the PI was assessed according to the prescription modification. Then PI are recorded by pharmacists in $\mathrm{ACT}-\mathrm{IP}^{\circledR}$, an online database (developed by the SFPC) allowing PIs documentation and analysis [26].

All PIs carried out from 1 January 2015 to 21 December 2015 were included in this study. They were analysed retrospectively to evaluate their clinical impact. After extraction of the ACT-IP ${ }^{\circledR}$ data, they were processed with the Excel ${ }^{\circledR}$ software.

PIs were excluded for the clinical impact evaluation in case of not interpretable data, prescription of medicines not available in the hospital or insufficient clinical relevance estimated by the pharmacist.

The selected PIs were gathered in 11 categories: anticoagulants, gastrointestinal drugs, analgesics/anti-inflammatory drugs, anti-infective drugs, psychotropic drugs, antidiabetic drugs, absorption-modifying drugs, injectable electrolytes and parenteral nutrition, cardiovascular drugs, immunosuppressive drugs and biologics and finally a group of miscellaneous drugs. Within each category, the PIs related to the same situation were grouped under the same item.

The potential clinical impact rating scale used [19] has 5 levels: minor, significant, major, critical and catastrophic. It is similar to the National Coordinating Council for Medication Error Reporting and Prevention (NCC MERP) scale used for categorizing ME [27]. The study scale was validated initially in a French study to evaluate the severity of the potential harm of ME reported by medication reconciliation. This scale was selected because of the equivalence of the ME consequences (sub- or supra-therapeutic dosage, untreated indications...) found by the reconciliation with those found by the medication review. A senior pharmacist who participated in medication review and a senior practitioner in rheumatology independently evaluated all included PIs. They considered the maximum severity that could occur if the DRP would not have been identified by pharmacist medication review. At the evaluation 
time, the 2 practitioners were aware on the DRP description, the drug(s) concerned, the patient's clinical, biological and pathophysiological data at the time of PI.

The similarity between the physician's evaluation and that of the pharmacist was estimated based on the number of items evaluated in an identical manner. The agreement between the 2 evaluators was estimated by the kappa coefficient of concordance (linear weighting) and for which the value close to 1 corresponds with the highest degree of concordance [28]. A threshold above 0.6 was used to identify a satisfactory level of concordance. Statistical analysis was performed using MedCalc ${ }^{\circledR}$ software.

\section{Results}

In one year, 1,313 prescriptions were analysed, representing 373 patients with a male/female ratio of 0.6. The mean age of the patients was 65 years [10-95] and the main reasons for hospitalization were chronic inflammatory rheumatism and bone diseases. The mean number of drugs initially prescribed was 8 . A total of 461 PIs were formulated, which represented $35 \%$ of the prescriptions analysed. Among these PIs, 310 were accepted by the clinicians (67.2\%). The DRP detected were mainly problems concerning improper route of administration $(31.7 \%)$, overdosage $(24.5 \%)$ and unjustified drugs $(17.6 \%)$. The details of DRP detected are recorded in fig. 1.

A total of 43 PIs were excluded, leaving 418 PIs (90.7\% of the PIs carried out) for the clinical significance evaluation. Those PI were considered as clinically non relevant (i.e., incomplete drug prescription and non-optimal dosage regimen without consequences for the patient), not interpretable (missing evaluation information) or related to medicines not available in the hospital. The details of the selection of PIs are presented in fig. 2. They were grouped into 171 items (examples of items are provided in table 2).

The rating of PIs clinical relevance according to the physician and the pharmacist is presented in table 3. For the physician, 235 PIs (56.2\%) had at least one significant impact versus 400 
PIs (95.7\%) for the pharmacist. One PI out of ten was major for the physician versus more than one PI out of five for the pharmacist. The physician considered that one PI $(0.2 \%)$ had a critical impact for the patient (major impact for the pharmacist). This PI concerned a supratherapeutic dosage for a cardiovascular drug: amlodipine for which 10 tablets were prescribed in error. No PI was evaluated as having a catastrophic clinical impact for the patient. For the physician, no PI in the anti-infective, psychotropic, absorption-modifying, antidiabetic and miscellaneous drug categories had a major impact. For the pharmacist, only the PIs in the absorption-modifying drug category had no major impact. The rates of similarity between the physician and the pharmacist, according to the categories and PIs items are presented in table 4. The physician and the pharmacist evaluated the potential clinical impact of $90 \mathrm{PI}$ items in the same manner (i.e., 52.6\% of the PI items). The rating of PIs items according to the professional and the clinical impact level is presented in table 5. The agreement between the physician and the pharmacist was estimated by a weighted kappa coefficient of 0.29 (95\% CI 0.19-0.39).

\section{Discussion}

To our knowledge, this is the first study to evaluate the clinical relevance of PIs carried out during medication review in rheumatology. The study shows a high level of PIs (35\%) in comparison to the data in the literature where it varies between $1 \%$ and $37 \%$ in France $[26,29]$. A previous study conducted in rheumatology [30] showed a lower rate of PIs (12.5\%). This difference may be explained by a strong pharmaceutical presence in the department for the previous study which allows the pharmacist to intervene before the prescription. In our study, the main problems noted were an improper administration $(31.7 \%)$, overdosages $(24.5 \%)$ and unjustified drugs $(17.6 \%)$. These results are consistent with the data in the literature [30-32]. 
The $67.2 \%$ acceptance rate of PIs by physicians was close to the rates found in the literature, which vary from $39 \%$ to $100 \%[26,29]$.

\section{Clinical relevance of pharmacists' interventions}

Globally, the majority of PIs were considered to have at least a significant impact $(95.7 \%$ for the pharmacist and $56.2 \%$ for the physician). More specifically, for the pharmacist, more than one PI out of five was major versus one PI out of ten for the physician. This means that it could have a temporary clinical consequence for the patient. Major PIs were especially those related to anticoagulants and injectable drugs (electrolytes and parenteral nutrition). The physician evaluated $43.8 \%$ of PIs as having a minor impact while the pharmacist estimated them at $4.3 \%$. However, the physician did not consider them useless (data not shown) and wanted them to be reported. The formulation of these PIs provides the opportunity to remind senior physicians and residents of good prescription practices.

Comparison with results in the literature is difficult because the methodologies used are varied (number and professions of evaluators, scales used, drug categories and types of PIs analysed, etc.). Nevertheless, in studies, most PIs were considered to have at least a significant impact $[14,15,21,22,33]$. For example, the expert group (2 geriatricians and 2 pharmacists) in the study by Ziane et al. considered that $55.2 \%$ of the PIs were at least significant [15]. The evaluation by Cortejoso et al. showed that $75.3 \%$ of the PIs were associated with errors categorized as significant [21].

In our study, a difference in the evaluation of the potential clinical impact was noted between the physician and the pharmacist. In general, the physician evaluated more moderately the clinical relevance of PIs than the pharmacist. This difference in risk assessment was noted in previous studies $[20,34]$. This variation may be explained by a different perception of iatrogenic risk for the patient by the two professionals. 
The highest difference of perception was observed in the gastrointestinal, immunosuppressive and biologics categories, the clinical significance of PIs was clearly higher for the pharmacist than for the physician. In the gastrointestinal category, $95.2 \%$ of the PIs were categorized as minor for the physician while these PIs were considered as significant $(91.7 \%)$ by the pharmacist. This difference was potentially explained by pharmacists' high sensitivity to the misuse of proton pump inhibitors PPI (i.e., unjustified indication, negative benefit-risk ratio). For the other categories, the divergence may be explained by the common use of these classes of medicines in rheumatology. Moreover, pharmacists can overestimate the impact of PIs related to medications that are at risk and/or costly (for example methotrexate, biologics).

The absence of divergence was observed for anticoagulants, absorption-modifying drugs and injectable drugs. These drug categories are mostly classes considered to present a risk for the patient with potential adverse events after overdosage, for example. Overall, even though $52.6 \%$ of the PI items were evaluated in the same manner by the pharmacist and the physician, the judgement agreement remained low (weighted kappa of 0.29). However, the judgment difference between the physician and the pharmacist was rarely important when they judged a PI differently. Such results had already been noted in the study by Bosma et al. where the weighted kappa coefficient was 0.3 [20].

\section{Strengths and limits of the study}

The clinical relevance assessment method seems to be a strong point of the study. In fact, few studies showed an independent evaluation of the potential clinical impact of PIs by physicians and pharmacists $[20,33]$. To our knowledge, no French study compared the evaluation of the clinical significance of PIs by a physician and a pharmacist. In many studies, the evaluation was carried out by a group of medical and/or pharmaceutical healthcare professionals who collectively analysed the potential clinical impact of PIs [14, 15, 17, 18, 21, 22, 33-35]. In this 
study, independent evaluation by two evaluators provided the opportunity to compare the medical and pharmaceutical opinions on PIs carried out during medication review in rheumatology.

However, the selection of PIs for evaluation was subjective and the reasons for exclusion of PIs are open to discussion. This selection was based on our professional experience, which was the case for other authors before us [16], simplified for evaluators the rating step. PIs concerning medications not listed in the hospital drug formulary were excluded because they constituted a drug management problem at the hospital and generally did not present a major risk. The inclusion of these PIs in the studies was frequently the cause of high rates of PIs without any clinical impact [15]. However, the presence of drugs not listed in the formulary can cause DRP: dosage error, non-equivalent substitution, absence of treatment, etc. [14].

Another limit to this study is related to the subjectivity of the evaluation. The affiliation of both evaluators with the study establishment may cause a bias in the rating of PIs. The pharmacist evaluator was one of the pharmacists involving in the medication review and the physician evaluator was part of the study ward. However, both evaluators are hospital practitioners with extensive knowledge of the rheumatology context. It may be considered that in light of their knowledge of the context, their opinion is pertinent.

Finally, it was a monocentric and retrospective study, the results of which were based on rheumatology practices. The results cannot be extrapolated to other types of therapeutic management.

\section{Conclusion}

The study shows that the pharmacist detected a high number of DRP with significant clinical relevance during medication review in rheumatology. The multidisciplinary evaluation of the 
PIs impact highlights the strong collaboration between pharmacists and physicians in rheumatology. This evaluation of the significance of medication review on the patient's clinical status is required to emphasize the importance of medication review and to increase the awareness of senior physicians on the risk related to prescriptions. In addition, the difference in physicians and pharmacists' points of view allows to compare opinions and improves both medical and pharmaceutical practices. This collaboration between physicians and pharmacists makes the pharmacists' intervention more effective, improves the quality of patient care and decreases the iatrogenic risk.

\section{Funding}

None.

\section{Conflicts of interest}

The authors declare that they have no conflicts of interest with regard to this work. 


\section{References}

[1] McDowell SE, Ferner HS, Ferner RE. The pathophysiology of medication errors: how and where they arise. Br J Clin Pharmacol. 2009;67(6):605-13.

[2] Michel P, Quenon JL, Lathelize M, Bru-Sonnet R, Perez C, Domecq S, Kret M. Enquête nationale sur les évènements indésirables graves associés aux soins 2009 (ENEIS 2) : descriptions des résultats 2009. Rapport final à la DREES; 2011.

[3] Gurwitz JH, Field TS, Avorn J, McCormick D, Jain S, Eckler M, et al. Incidence and preventability of adverse drug events in nursing homes. Am J Med. 2000;109(2):87-94.

[4] Kuo GM, Touchette DR, Marinac JS. Drug errors and related interventions reported by United States clinical pharmacists: the American College of Clinical Pharmacy practice-based research network medication error detection, amelioration and prevention study. Pharmacotherapy. 2013;33(3):253-65.

[5] Bates DW, Cullen DJ, Laird N, Petersen LA, Small SD, Servi D, et al. Incidence of adverse drug events and potential adverse drug events. Implications for prevention. ADE Prevention Study Group. JAMA. 1995;274(1 ):29-34.

[6] Griese-Mammen N, Hersberger KE, Messerli M, Leikola S, Horvat N, van Mil JWF et al. PCNE definition of medication review: reaching agreement. Int J Clin Pharm. 2018. doi: 10.1007/s11096-018-0696-7

[7] Leape LL, Cullen DJ, Clapp MD, Burdick E, Demonaco HJ, Erickson JI, et al. Pharmacist participation on physician rounds and adverse drug events in the intensive care unit. JAMA. 1999;282(3):267-70.

[8] Scarsi KK, Fotis MA, Noskin GA. Pharmacist participation in medical rounds reduces medication errors. Am J Health Syst Pharm. 2002;59(21):2089-92. 
[9] Kucukarslan SN, Peters M, Mlynarek M, Nafziger DA. Pharmacists on rounding teams reduce preventable adverse drug events in hospital general medicine units. Arch Intern Med. 2003;163(17):2014-8.

[10] Boyko WL, Yurkowski PJ, Ivey MF, Armitstead JA, Roberts BL. Pharmacist influence on economic and morbidity outcomes in a tertiary care teaching hospital. Am J Health Syst Pharm. 1997;54(14):1591-5.

[11] Haig GM, Kiser LA. Effect of pharmacist participation on a medical team on costs, charges, and length of stay. Am J Hosp Pharm. 1991;48(7):1457-62.

[12] Bond CA, Raehl CL. Clinical pharmacy services, pharmacy staffing, and hospital mortality rates. Pharmacotherapy. 2007;27(4):481-93.

[13] Bright JM, Tenni PC. The Clinical Services Documentation (CSD) System for Documenting Clinical Pharmacists' Services. Aust J Hosp Pharm. 2000;30(1):10-5.

[14] Guignon AM, Grain F, Allenet B, Brudieu E, Barjhoux C, Bosson JL, et al. Assessment of the clinical impact of pharmacists' recommendations in a medical care unit. J Pharm Clin. 2001;20(2):118-23.

[15] Ziane A, Ngami C, Youb R, Atri MH, Aikpa R, Kabirian F, Fauvelle F. Evaluating the quality of pharmacists's interventions in older patient than 75 years. J Pharm Clin. 2013; 32(4):243-9.

[16] Hatoum HT, Hutchinson RA, Elliott LR, Kendzierski DL. Physicians' review of significant interventions by clinical pharmacists in inpatient care. Drug Intell Clin Pharm. 1988;22(12):980-2.

[17] Bayliff CD, Einarson TR. Physician assessment of pharmacists' interventions : a method of estimating cost avoidance and determining quality assurance. Can J Hosp Pharm. 1990;43(4):167-71. 
[18] Overhage JM, Lukes A. Practical, reliable, comprehensive method for characterizing pharmacists' clinical activities. Am J Health Syst Pharm. 1999;56(23):2444-50.

[19] Doerper S, Godet J, Alexandra JF, Allenet B, Andres E, Bedouch P, et al. Development and multi-centre evaluation of a method for assessing the severity of potential harm of medication reconciliation errors at hospital admission in elderly. Eur $\mathbf{J}$ Intern Med. 2015;26(7):491-7.

[20] Bosma L, Jansman FG, Franken AM, Harting JW, Van den Bemt PM. Evaluation of pharmacist clinical interventions in a Dutch hospital setting. Pharm World Sci. 2008;30(1):31-8.

[21] Cortejoso L, Dietz RA, Hofmann G, Gosch M, Sattler A. Impact of pharmacist interventions in older patients: a prospective study in a tertiary hospital in Germany. Clin Interv Aging. 2016; 11: 1343-1350.

[22] Pérez-Moreno MA, Rodriguez-Camacho JM, Calderon-Hernanz B, Comas-Diaz B, Tarradas-Torras J. Clinical relevance of pharmacist intervention in an emergency department. Emerg Med J. 2016; 0:1-7.

[23] Juste M. Recommendation of good practice in clinical pharmacy. Analysis of prescription and levels of pharmaceutical analysis. J Pharm Clin. 2012; 47: 293-5. [24] The French Society of Clinical Pharmacy. Niveaux d'analyse pharmaceutique. Available at: http://sfpc.eu/fr/item1/finish/34-documents-sfpc-public/454sfpcrecommandationbppharmaciecliniqueniveauanalysesept12/0.html (accessed 21 august 2018).

[25] Allenet B, Bedouch P, Rose FX, Escofier L, Roubille R, Charpiat B et al. Validation of an instrument for the documentation of clinical pharmacists interventions. Pharm World Sci. 2006;28(4): 181-8. 
[26] Bedouch P, Sylvoz N, Charpiat B, Juste M, Roubille R, Rose FX et al. Trends in pharmacists' medication order review in French jospitals from 2006 to 2009: analysis of pharmacists' interventions from the Act-IP ${ }^{\odot}$ website observatory. J Clin Pharm Ther. 2015;40(1):32-40.

[27] The National Coordinating Council for Medication Error Reporting, Prevention. NCC M ERP Index for Categorizing Medication Errors. Available at: http://www.nccmerp.org/sites/de fault/files/indexColor2001-06-12.pdf (accessed 13 april 2018).

[28] Landis JR, Koch GG. The measurement of observer agreement for categorical data. Biometrics. 1977;33(1):159-74.

[29] Morice E, Gabriel-Bordenave C, Auclair V, Juste M, Roberge C. Evaluation of prescription checking practices by French hospital Pharmacists. Pharm Hosp Clin. 2011;46(3):146-155.

[30] Coursier S, Bontemps H, Brantus JF, Allenet B. Economic impact of pharmacist's interventions: illustration in a rheumatology ward. J Pharm Belg. 2008;63(4):103-9.

[31] Bedouch P, Charpiat B, Conort O, Rose F-X, Escofier L, Juste M et al. Assessment of clinical pharmacists' interventions in French hospitals: results of a multicenter study. Ann Pharmacother. 2008;42(7):1095-103.

[32] Fernandez-Llamazares CM, Calleja-Hernández M-A, Manrique-Rodríguez S, Pérez-Sanz C, Duran-Garcia E, Sanjurjo-Saez M. Prescribing errors intercepted by clinical pharmacists in paediatrics and obstetrics in a tertiary hospital in Spain. Eur $\mathbf{J}$ Clin Pharmacol. 2012;68(9):1339-45.

[33] Bondesson A, Holmdahl L, Midlöv P, Höglund P, Andersson E, Eriksson T. Acceptance and importance of clinical pharmacists' LIMM-based recommendations. Int $\mathrm{J}$ Clin Pharm. 2012;34(2):272-6. 
[34] Dale MA, Copeland R, Barton R. Prescribing errors on medical wards and the impact of clinical pharmacists. Int J Pharm Pract. 2003;11(1):19-24.

[35] Modig S, Holmdahl L, Bondesson Å. Medication reviews in primary care in Sweden: importance of clinical pharmacists' recommendations on drug-related problems. Int J Clin Pharm. 2016;38(1):41-5. 
Fig. 1: Drug-related problems identified during the medication review (in 2015, for the 1,313 prescriptions analysed)

Fig. 2: Results of the selection of PIs to be analyzed 
Figure 1

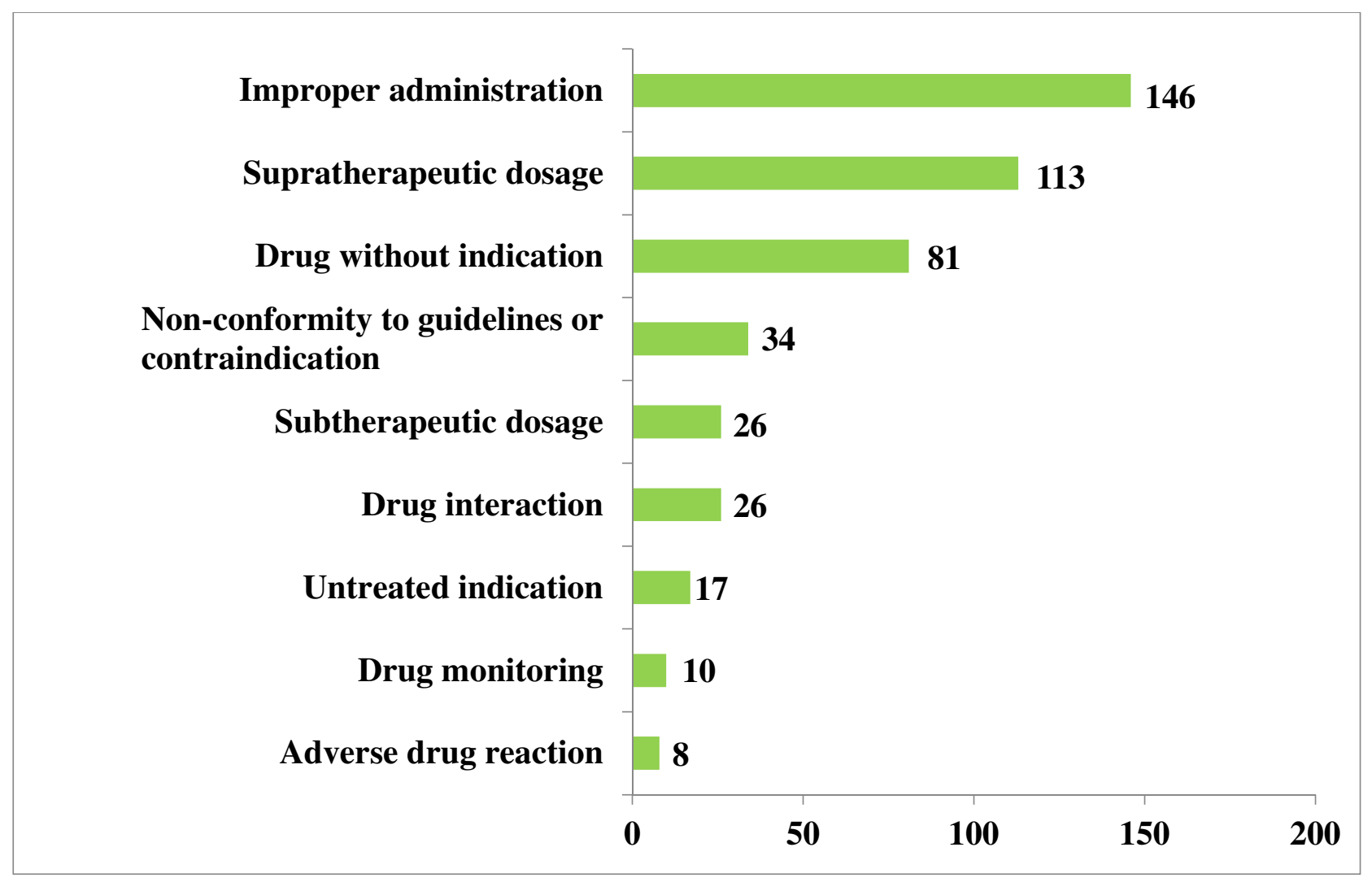


Figure 2

Retrospective collection of PIs carried out for 12 months for prescription analyses (extraction from the ACT-IP® tool)

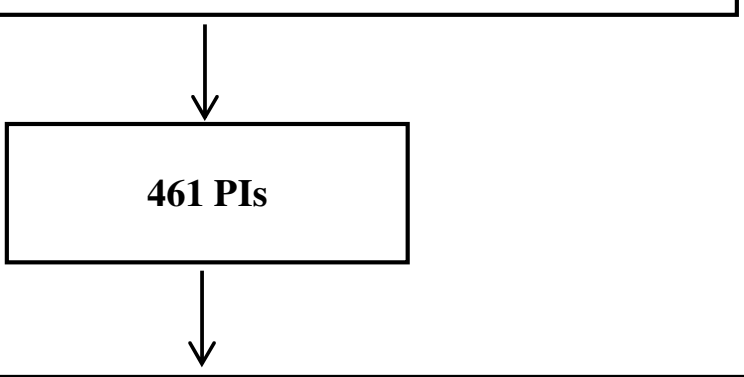

Exclusion of PIs (n)

- Non hospital formulary medications (12)

- PIs considered to be non-relevant (16): incomplete drug prescription and non-optimal dosage regimen without consequences for the patient

- Incomplete or insufficient data to evaluate the potential clinical impact of the PI (15)

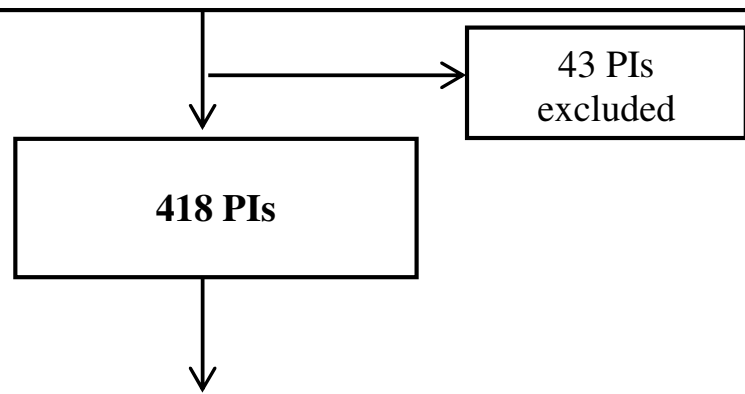

Sorting of PIs according to the categories involved

Grouping PIs by item

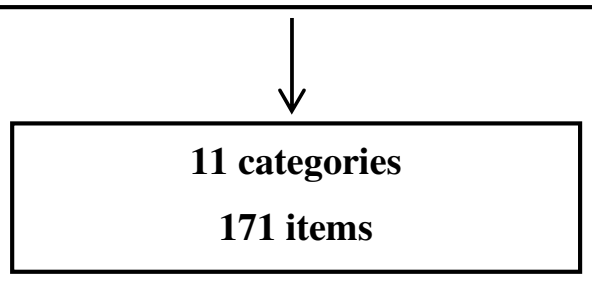


Table 1: DRP and pharmacists' intervention considering the classification of the French Society of Clinical Pharmacy (SFPC)

\section{Drug-related problems}

1. Non conformity to guidelines or contra-indication

2. Untreated indication

3. Subtherapeutic dosage

4. Supratherapeutic dosage

5. Drug without indication

6. Drug interaction

7. Adverse drug reaction

8. Improper administration

9. Failure to receive drung

10. Drug monitoring

\section{Pharmacist's interventions}

1. Addition of a new drug

2. Drug discontinuation

3. Drug switch

4. Change of administration route

5. Drug monitoring

6. Administration mode optimisation

7. Dose adjustment 
Table 2: Number and examples of PI items used in the clinical relevance study and grouped by category

PIs related to the same situation were grouped under the same situation, i.e. 171 items

\section{Category $=\mathrm{N}$ number of PIs Examples of items (n number of PIs carried out per items)}

carried out per category

\begin{tabular}{lcl}
\hline Injectable electrolytes & and & - Medication prescribed without justified indication: injectable potassium with \\
parenteral nutrition = 5 & & kaliemia at $4.4 \mathrm{mmol} / \mathrm{l}(1)$ \\
& & - Intravenous/oral conversion: injectable potassium and moderate hypokalaemia \\
& $(1)$
\end{tabular}

Antidiabetic drugs = 9

- Supra-therapeutic dosage: full dose of sitagliptine in a patient with renal failure (1)

- Supra-therapeutic dosage: 2 brands of metformin (2 different formulations) (1)

- Supra-therapeutic dosage: 2 doses of insulin in the morning (included and not included in the protocol) (1)

Anti-infective drugs $=14$ - Ceftriaxone: incomplete prescription without the solute, volume in dilution, duration of the perfusion (6)

- Prescription of amoxicillin although there is a resistance to ampicillin on the antimicrobial susceptibility testing (1)

- Duration of gentamicin antibiotic therapy not specified (1)

\begin{tabular}{|c|c|}
\hline Absorption-modifying drugs = 16 & $\begin{array}{l}\text { - Hypocalcaemia and absence of therapeutic effect for valid medical indication (3) } \\
\text { - Administration plan not optimal: calcium administration time not adjusted in } \\
\text { relation to the other medicines (6) }\end{array}$ \\
\hline Anticoagulants $=19$ & $\begin{array}{l}\text { - INR below 2: Sub-therapeutic dosage of fluindione (5) } \\
\text { - INR above 3: Supra-therapeutic dosage of fluindione (4) } \\
\text { - Recommendation not to combine rivaroxaban and carbamazepine (1) }\end{array}$ \\
\hline Cardiovascular drugs $=\mathbf{2 0}$ & $\begin{array}{l}\text { - Metoprolol / simvastatin: prescription not adapted to the breakability of the tablet } \\
\text { (2) } \\
\text { - Rilmenidine: inappropriate medicine in elderly patients (admitted for fall-related } \\
\text { syndrome) (4) } \\
\text { - Supra-therapeutic dosage: } 2 \text { prescriptions of lysine acetylsalicylate (1) }\end{array}$ \\
\hline $\begin{array}{l}\text { Immunosuppressive drugs and } \\
\text { biologics }=\mathbf{3 4}\end{array}$ & $\begin{array}{l}\text { - Contraindication: Ciclosporin and colchicine (1) } \\
\text { - Abatacept: usually SC route (pen) and prescription in vial for IV injection in the } \\
\text { hospital (2) } \\
\text { - Prescription of methotrexate every day in the software (2) }\end{array}$ \\
\hline Miscellaneous drugs $=52$ & $\begin{array}{l}\text { - Risedronate: Problem with administration modalities (2) } \\
\text { - Supra-therapeutic dosage: Allopurinol not adapted to renal function (2) } \\
\text { - Contraindication: levodopa and metochlopramide (2) }\end{array}$ \\
\hline Psychotropic drugs $=55$ & $\begin{array}{l}\text { - Benzodiazepine overdosage in patients over } 65 \text { years of age (18) } \\
\text { - Supra-therapeutic hydroxyzine dosage in elderly patients (2) }\end{array}$ \\
\hline Gastrointestinal drugs = 84 & $\begin{array}{l}\text { - No indication found in the medical record for proton pump inhibitors (41) } \\
\text { - Phloroglucinol / trimebutine / metoclopramide / domperidone / loperamide: } \\
\text { prescription to be suspended due to non-administration for several days (8) }\end{array}$ \\
\hline $\begin{array}{l}\text { Analgesics and Anti- } \\
\text { inflammatory drugs }=110\end{array}$ & $\begin{array}{l}\text { - IV / PO conversion (ketoprofen / acetaminophen / tramadol) (14) } \\
\text { - Morphine: Problem with the choice of extended- and immediate release doses } \\
\text { (sub-therapeutic) and inter-doses too low in relation to the baseline dose (12) } \\
\text { - Supra-therapeutic dosage of acetaminophen: } 4 \mathrm{~g} \text { systematically in a patient over } \\
75 \text { years of age (11) }\end{array}$ \\
\hline
\end{tabular}


Table 3: Clinical relevance of PIs in terms of the category according to the physician and the pharmacist $\mathbf{n}(\%)$

\begin{tabular}{|c|c|c|c|c|c|c|c|c|}
\hline & \multicolumn{2}{|c|}{ Minor } & \multicolumn{2}{|c|}{ Significant } & \multicolumn{2}{|c|}{ Major } & \multicolumn{2}{|c|}{ Critical } \\
\hline & Pharmacist & Physician & Pharmacist & Physician & Pharmacist & Physician & Pharmacist & Physician \\
\hline Totals & $18(4.3)$ & $183(43.8)$ & 308 (73.7) & $191(45.7)$ & $92(22.0)$ & $43(10.3)$ & $\mathbf{0}(\mathbf{0})$ & $1(5.0)$ \\
\hline $\begin{array}{l}\text { Analgesics and Anti-inflammatory } \\
\text { drugs }\end{array}$ & $3(2.7)$ & $32(29.1)$ & $65(59.1)$ & $51(46.4)$ & $42(38.2)$ & $27(24.5)$ & $0(0)$ & $0(0)$ \\
\hline Antidiabetic drugs & $0(0)$ & $0(0)$ & $7(77.8)$ & $9(100)$ & $2(22.2)$ & $0(0)$ & $0(0)$ & $0(0)$ \\
\hline Anticoagulants & $1(5.3)$ & $1(5.3)$ & $5(26.3)$ & $9(47.4)$ & $13(68.4)$ & $9(47.4)$ & $0(0)$ & $0(0)$ \\
\hline Absorption-modifying drugs & $0(0)$ & $2(12.5)$ & $16(100)$ & $14(87.5)$ & $0(0)$ & $0(0)$ & $0(0)$ & $0(0)$ \\
\hline $\begin{array}{l}\text { Injectable electrolytes and } \\
\text { parenteral nutrition }\end{array}$ & $0(0)$ & $0(0)$ & $3(60.0)$ & $3(60.0)$ & $2(40.0)$ & $2(40.0)$ & $0(0)$ & $0(0)$ \\
\hline Psychotropic drugs & $4(7.3)$ & $13(23.6)$ & $49(89.1)$ & $42(76.4)$ & $2(3.6)$ & $0(0)$ & $0(0)$ & $0(0)$ \\
\hline Anti-infective drugs & $1(7.1)$ & $3(21.4)$ & $11(78.6)$ & $11(78.6)$ & $2(14.3)$ & $0(0)$ & $0(0)$ & $0(0)$ \\
\hline $\begin{array}{l}\text { Immunosuppressive drugs and } \\
\text { biologics }\end{array}$ & $0(0)$ & $20(58.9)$ & $13(38.2)$ & $11(32.4)$ & $21(61.8)$ & $3(8.8)$ & $0(0)$ & $0(0)$ \\
\hline Gastrointestinal drugs & $6(7.1)$ & $80(95.2)$ & $77(91.7)$ & $3(3.6)$ & $1(1.2)$ & $1(1.2)$ & $0(0)$ & $0(0)$ \\
\hline Miscellaneous drugs & $3(5.8)$ & $25(48.1)$ & $45(86.5)$ & $27(51.9)$ & $4(7.7)$ & $0(0)$ & $0(0)$ & $0(0)$ \\
\hline Cardiovascular drugs & $0(0)$ & $7(35.0)$ & $17(85.0)$ & $11(55.0)$ & $3(15.0)$ & $1(5.0)$ & $0(0)$ & $1(5.0)$ \\
\hline
\end{tabular}

No IP was classified as catastrophic by the physician and the pharmacist. 
Table 4: Similarity of the clinical relevance of PIs for the physician and the pharmacists according to the category

\begin{tabular}{lc}
\hline \multicolumn{1}{c}{ Categories } & $\begin{array}{c}\text { Number of items with a similar impact for } \\
\text { the physician/pharmacist (\%) }\end{array}$ \\
\hline Analgesics and Anti-inflammatory drugs & $5(78.1)$ \\
Antidiabetic drugs & $6(75.0)$ \\
Anticoagulants & $5(71.4)$ \\
Absorption-modifying drugs & $4(66.6)$ \\
Injectable electrolytes and parenteral nutrition & $3(60.0)$ \\
Psychotropic drugs & $16(59.3)$ \\
Anti-infective drugs & $5(55.6)$ \\
Immunosuppressive drugs and biologics & $7(46.7)$ \\
Gastrointestinal drugs & $6(33.3)$ \\
Miscellaneous drugs & $10(32.3)$ \\
Cardiovascular drugs & $3(23.1)$ \\
\hline
\end{tabular}


Table 5: Clinical relevance of PIs for the physician and the pharmacist according to the clinical impact level

\begin{tabular}{|c|c|c|c|c|c|c|}
\hline & \multicolumn{6}{|c|}{ Physician } \\
\hline \multirow{6}{*}{ 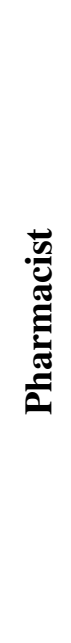 } & Clinical impact level & Minor & Significant & Major & Critical & Total \\
\hline & Minor & 15 & 1 & 0 & 0 & 16 \\
\hline & Significant & 56 & 63 & 5 & 0 & 124 \\
\hline & Major & 2 & 17 & 11 & 1 & 31 \\
\hline & Critical & 0 & 0 & 0 & 0 & $\mathbf{0}$ \\
\hline & Total & 73 & 81 & 16 & 1 & 171 \\
\hline
\end{tabular}

The weighted $\kappa$ was calculated from the data in this table. 